\title{
Penerapan Metode DMAIC Untuk Minimalisasi Material Scrap Pada Warehouse Packaging Marsho PT. SMART Tbk. Surabaya
}

\author{
Muhammad Habib Isna Nur Asnan*) dan Fakhrina Fahma \\ Program Studi Teknik Industri Universitas Sebelas Maret \\ Jl. Ir. Sutami, 36 A, Surakarta, Indonesia
}

DOI: 10.20961/performa.18.1.21764

\begin{abstract}
Abstrak
Sebagai salah satu perusahaan manufaktur yang bergerak di bidang pangan, PT SMART Tbk. Surabaya sering mengalami masalah mengenai kualitas pada material yang disimpan di Warehouse Packaging Marsho yaitu sering ditemukannya material scrap. Berdasarkan data 1 April 2017 sampai dengan 15 Februari 2015, persentase material scrap tersebut semakin meningkat setiap bulannya yakni dari 5\% menjadi 23\%. Tujuan dari penelitian ini adalah untuk meminimalisasi material scrap pada Warehouse Packaging Marsho PT. SMART Tbk. Surabaya menggunakan metode Metode DMAIC yakni dengan mengimplementasikan tahapan Define, Measure, Analyze, Improve, dan Control. Hasil yang didapatkan yakni penyebab material scrap paling dominan adalah operator malas menempatkan material sesuai dengan ketentuan (batch tertua). Dengan demikian perlu dilakukan adanya perbaikan untuk meminimalisasi material scrap tersebut yaitu dengan melakukan briefing rutin oleh pihak PIC Area Warehouse Packaging Marsho sebelum kegiatan operasional dimulai.
\end{abstract}

Kata kunci: Kualitas, Cacat, Material scrap, DMAIC, Warehouse

Abstract

As one of the manufacturing companies engaged in food, PT SMART Tbk. Surabaya often having problem about the quality of materials stored in Warehouse Packaging Marsho which is often founded scrap materials. Based on the data from April 1 ${ }^{\text {st }}, 2017$ to February 15 $5^{\text {th }}$,2015, the percentage of scrap material is increasing every month from 5\% to 23\%. The purpose of this research is to minimize the scrap materials in Warehouse Packaging Marsho PT. SMART Tbk. Surabaya using DMAIC method by implementing Define, Measure, Analyze, Improve, and Control stages. The results are the most dominant cause of scrap is the laziness of operator to place materials in accordance with the provisions (general batch). Thus, it is necessary to make improvements to minimize the scrap material by doing a routine briefing from PIC Area Warehouse Packaging Marsho before the operational activities begin.

Keywords: Quality, Defect,Scrap material, DMAIC,Warehouse

\section{Pendahuluan}

PT. Sinar Mas Agro Resources and Technology (PT. SMART Tbk) Surabaya merupakan pabrik pengolahan minyak goreng dengan bahan baku CPO (Crude Palm Oil) dari buah kelapa sawit. Salah satu masalah mengenai kualitas yang sering ditemui adalah masalah material yang disimpan di Warehouse Packaging produk margarin dan shortening (Marsho) yaitu sering ditemukannya material yang scrap. Material scrap adalah bahan yang mengalami kerusakan di dalam proses produksi (Tebae dkk, 2016). Berdasarkan data 1 April 2017 sampai dengan 15 Februari 2018, persentase material scrap tersebut semakin meningkat setiap bulannya yakni dari 5\% menjadi 23\%. Material scrap tersebut dapat berasal dari material tidak memenuhi spesifikasi yang ditetapkan perusahaan (afkir dari supplier), pengembalian sisa material dari departemen produksi ke Warehouse Packaging (sisa produksi), kesalahan material handling, dan produk sudah tidak diproduksi lagi (discontinue).

Berdasarkan pemaparan masalah diatas maka dilakukan penelitian untuk meminimalisasi material scrap pada Warehouse Packaging Marsho PT. SMART Tbk. Surabaya menggunakan metode DMAIC. DMAIC merupakan sebuah metode perbaikan kualitas yang langsung memecahkan masalah yang berkaitan dengan mutu sebuah produk hingga pada penyebab utamanya (Tan, 2012). Menurut Siregar dan Mutiara (2019) metode DMAIC merupakan pendekatan untuk meningkatkan kualitas suatu proses atau produk sehingga dapat mengurangi atau menghilangkan kecacatan yang merugikan perusahaan.. Metode DMAIC 
mengimplementasikan tahap define, measure, analyze, improve, dan control. Metode DMAIC melibatkan sejumlah tool dan teknik baik statistik maupun non statistik (Wibisono \& Suteja, 2013).

Siregar dan Mutiara (2019) melakukan penelitian untuk mengetahui dan menganalisis kerusakan barang obat dan alat kesehatan yang disimpan di gudang PT. Dakota Logistik Indonesia menggunakan metode DMAIC. Permasalahan yang ditemukan adalah banyaknya klaim barang dalam gudang PT. Dakota Logistik Indonesia yang mengakibatkan tingginya biaya klaim barang. Nasution dan Sodikin (2018) mengidentifikasi tingkat kecacatan dominan, menganalisis factor penyebab kecacatan dominan serta usulan perbaikan guna peningkatan kualitas proses produksi karton box dengan menggunakan metode DMAIC dan Fuzzy FMEA. Sedangkan Yunita dan Adi (2019) mengidentifikasi permasalahan proses produksi komponen guide pada supplier PT. X dengan metode DMAIC. Penyebab permasalahan yang ditemukan adalah adanya perbedaan jumlah stock opname komponen guide yang lebih dari 50\% dibandingkan dengan material subkontrak lainnya.

\section{Metode Penelitian}

Metode penelitian ini menggunakan metode DMAIC. Menurut Gultom dkk. (2013), metode DMAIC digunakan untuk mengidentifikasi dan mengeleminasi pemborosan yang ada. Penelitian ini hanya dilakukan pada seksi Warehouse Packaging Marsho PT. SMART Tbk. Surabaya dan data yang digunakan adalah data scrap bulan April 2017 sampai dengan 15 Februari 2018 sebagai pembatas serta asusmsi yang digunakan pada penelitian ini adalah faktor pengganggu (block) pada pemberian nilai pada Severity (S), Occurrence (O), dan Detection (D) tidak ada.

Sebelum melakukan identifikasi risiko, peneliti terlebih dahulu melakukan rekapitulasi data scrap pada seksi Warehouse Packaging Marsho berdasarkan sistem SAP PT. SMART Tbk. Surabaya kemudian dilakukan identifikasi risiko menggunakan diagram SIPOC proses penerimaan material sisa produksi. Datadata tersebut kemudian dilakukan pengukuran risiko menggunakan diagram pareto. Menurut Utami dkk. (2012), diagram pareto adalah sebuah distribusi frekuensi dari data yang paling besar sampai yang paling kecil. Sehingga diagram pareto digunakan untuk mengetahui penyebab scrap yang paling dominan untuk diselesaikan.

Setelah penyebab risiko paling dominan, kemudian dilakukan analisis risiko dengan menghitung nilai Risk Priority Number (RPN) penyebab material scrap menggunakan metode FMEA berdasarkan hasil brainstorming dengan pihak PIC Area Warehouse Packaging Marsho dan pihak PPIC. Melalui metode FMEA akan diketahui secara pasti faktor penyebab dominan terjadinya cacat produk sesuai dengan nilai RPN (Hariastuti, 2015). Menurut Adrianto (2015), rumus yang digunakan untuk menghitung RPN yaitu :

$\mathrm{RPN}=$ Severity $\mathrm{x}$ Occurance $\mathrm{x}$ Detection

Kemudian dilakukan evaluasi risiko terhadap nilai RPN tertinggi dengan menentukan usulan perbaikan menggunakan metode Five Why's Analysis agar material scrap dapat diminimalisasi. Setiap sumber masalah akan ditentukan apa penyebabnya sampai dengan lima tahap pertanyaan mengapa sehingga akar permasalahan dapat ditemukan dan dicari solusinya (Basuki dkk, 2015). Tahapan terakhir yaitu dilakukan pengendalian terhadap usulan perbaikan yang telah diberikan untuk meminimalisasi material scrap.

\section{Hasil dan Pembahasan}

\subsection{Define}

Berdasarkan hasil rekapitulasi data scrap pada seksi Warehouse Packaging Marsho PT. SMART Tbk. Surabaya, dapat diketahui bahwa jumlah material scrap pada seksi tersebut mengalami peningkatan dari 5\% menjadi 23\% sejak bulan April 2017 hingga bulan Februari 2018. Lebih jelasnya dijabarkan pada Tabel 1.

Dalam memudahkan penggambaran tahapan proses penerimaan material sisa dari departemen produksi hingga material disimpan pada Warehouse Packaging Marsho yang dapat menimbulkan terjadinya material scrap, maka digunakan Diagram SIPOC (Supplier-Input-Process-Output-Customer). Bagian yang dapat menimbulkan terjadinya material scrap terdapat pada bagian operator Warehouse Packaging yaitu ketika operator Warehouse Packaging melakukan penyimpanan barang dan melakukan update kartu stock dan Daftar Status Produk (DSP). Lebih jelasnya dijabarkan pada gambar 1. 
Tabel 1. Rekapitulasi Material Scrap Pada Seksi Warehouse Packaging Marsho PT. SMART Tbk. Surabaya

\begin{tabular}{|c|c|c|c|c|c|c|c|}
\hline \multirow{3}{*}{ Bulan } & \multicolumn{7}{|c|}{ Kuantitas (Pcs) } \\
\hline & \multicolumn{5}{|c|}{ Jenis Material } & \multirow[b]{2}{*}{ Total } & \multirow[b]{2}{*}{ Persentase } \\
\hline & Karton & \begin{tabular}{|c|} 
Plastic \\
Pail \\
\end{tabular} & $\begin{array}{r}\text { Plastic } \\
\text { LDPE }\end{array}$ & Steel & $\begin{array}{c}\text { Lid Tin } \\
\text { Can }\end{array}$ & & \\
\hline April & 482 & 0 & 0 & 0 & 0 & 482 & $5 \%$ \\
\hline Mei & 0 & 0 & 0 & 0 & 0 & 0 & $0 \%$ \\
\hline Juni & 0 & 0 & 0 & 0 & 0 & 0 & $0 \%$ \\
\hline Juli & 7 & 900 & 160 & 0 & 0 & 1067 & $11 \%$ \\
\hline Agustus & 0 & 0 & 0 & 0 & 0 & 0 & $0 \%$ \\
\hline September & 0 & 0 & 0 & 0 & 0 & 0 & $0 \%$ \\
\hline Oktober & 289 & 0 & 0 & 0 & 0 & 289 & $3 \%$ \\
\hline November & 361 & 0 & 0 & 0 & 0 & 361 & $4 \%$ \\
\hline Desember & 0 & 0 & 0 & 0 & 0 & 0 & $0 \%$ \\
\hline Januari & 5320 & 0 & 0 & 3 & 0 & 5323 & $54 \%$ \\
\hline Februari & 1904 & 335 & 0 & 0 & 41 & 2280 & $23 \%$ \\
\hline Total & 8363 & 1235 & 160 & 3 & 41 & \multirow{2}{*}{\multicolumn{2}{|c|}{9802}} \\
\hline \multicolumn{6}{|c|}{ Grand Total } & & \\
\hline
\end{tabular}

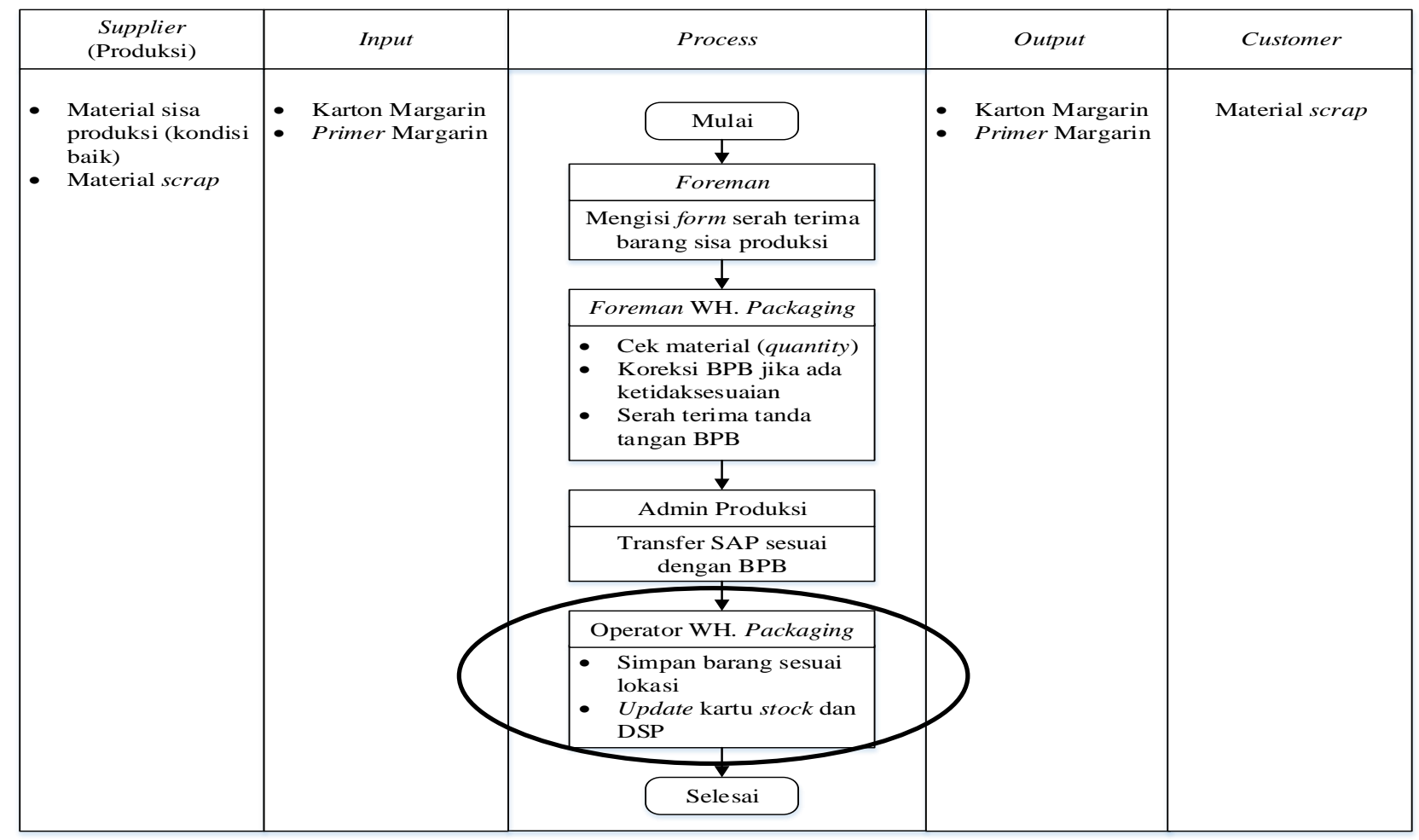

Gambar 1. Diagram SIPOC Penerimaan Material Sisa Produksi Pada Seksi Warehouse Packaging Marsho

\subsection{Measure}

Berdasarkan rekapitulasi data penyebab material scrap tersebut, maka dibuatlah Diagram Pareto untuk mengetahui penyebab material scrap yang harus diprioritaskan untuk diselesaikan. Diagram pareto merupakan sebuah grafik untuk memetakan masalah dalam urutan frekuensi menurun (Soetjitro, 2010). Kejadian disusun menurut ukurannya, dari yang paling besar di sebelah kiri ke yang paling kecil di sebelah kanan (Rusdianto dkk, 2011). Berdasarkan hasil Diagram Pareto penyebab utama material scrap pada seksi Warehouse Packaging Marsho PT. SMART Tbk. Surabaya secara berurutan adalah discontinue, sisa produksi, material handling, desain lama, beban marketing, dan permintaan PPIC. Berikut ini merupakan Diagram Pareto data penyebab material scrap tersebut. 


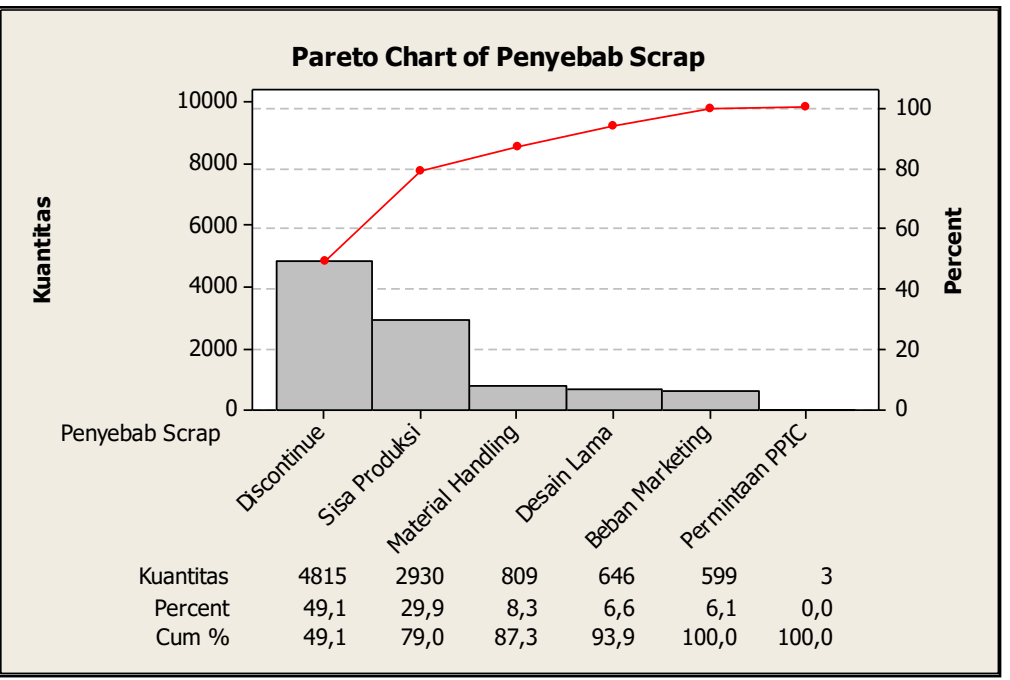

Gambar 2. Diagram Pareto Penyebab Material Scrap Pada Seksi Warehouse Packaging Marsho

Berdasarkan hasil tersebut, maka penyebab material scrap yang perlu diprioritaskan untuk diselesaikan dalam upaya minimalisasi material scrap pada seksi Warehouse Packaging Marsho PT. SMART Tbk. Surabaya adalah produk discontinue dan sisa produksi.

\subsection{Analyze}

Setelah mengetahui penyebab material scrap yang perlu diprioritaskan untuk diselesaikan, selanjutnya dilakukan analisis risiko yang dilakukan melalui 2 tahapan yaitu penilaian risiko dengan menggunakan metode Failure Mode and Effect Analysis (FMEA) serta penentuan probabilitas konsekuensi dari penyebab material scrap. Analisis risiko ini dilakukan untuk mengetahui nilai Risk Priority Number (RPN) tertinggi yang kemudian nilai RPN tertinggi tersebut akan dipriotitaskan untuk diselesaikan dengan mencari solusi pada tahapan improve.

Berikut ini merupakan tabel analisis risiko dan perhitungan RPN penyebab material scrap periode bulan April 2017 sampai dengan bulan Februari 2018.

Tabel 2. Analisis Risiko dan Perhitungan Risk Priority Number (RPN) Penyebab Material Scrap Pada Seksi Warehouse Packaging Marsho

\begin{tabular}{|c|c|c|c|c|c|c|c|c|}
\hline $\begin{array}{l}\text { Deskripsi } \\
\text { Proses }\end{array}$ & $\begin{array}{c}\text { Mode } \\
\text { Kegagalan } \\
\text { Potensial }\end{array}$ & $\begin{array}{c}\text { Akibat } \\
\text { Potensial dari } \\
\text { Kegagalan }\end{array}$ & $\mathbf{S}$ & $\begin{array}{c}\text { Penyebab } \\
\text { Potensi } \\
\text { Kegagalan }\end{array}$ & $\mathbf{O}$ & Metode Deteksi & D & RPN \\
\hline \multirow{6}{*}{$\begin{array}{l}\text { Penyimpanan } \\
\text { material di } \\
\text { Warehouse } \\
\text { Packaging } \\
\text { Marsho }\end{array}$} & \multirow[t]{3}{*}{ Discontinue } & \multirow{3}{*}{$\begin{array}{l}\text { Material yang } \\
\text { sudah tidak } \\
\text { digunakan } \\
\text { banyak }\end{array}$} & \multirow[t]{3}{*}{7} & $\begin{array}{l}\text { Persediaan } \\
\text { material di } \\
\text { gudang banyak }\end{array}$ & 8 & $\begin{array}{l}\text { Pengadaan material } \\
\text { sebatas secukupnya }\end{array}$ & 4 & 224 \\
\hline & & & & $\begin{array}{l}\text { Customer sudah } \\
\text { tidak memesan } \\
\text { produk lagi }\end{array}$ & 4 & $\begin{array}{l}\text { Melakukan follow up } \\
\text { rencana customer } \\
\text { kedepan secara detail }\end{array}$ & 4 & 112 \\
\hline & & & & $\begin{array}{l}\text { Hasil } \\
\text { forecasting } \\
\text { PPIC tidak } \\
\text { akurat }\end{array}$ & 5 & $\begin{array}{l}\text { Allowance } \\
\text { forecasting } \\
\text { disesuaikan }\end{array}$ & 3 & 105 \\
\hline & \multirow[t]{3}{*}{$\begin{array}{l}\text { Sisa } \\
\text { Produksi }\end{array}$} & \multirow[t]{3}{*}{$\begin{array}{l}\text { FIFO tidak } \\
\text { berjalan } \\
\text { dengan baik }\end{array}$} & \multirow[t]{3}{*}{6} & $\begin{array}{l}\text { Penyimpanan } \\
\text { material di rak } \\
\text { tidak tertata }\end{array}$ & 8 & $\begin{array}{l}\text { Memperbaiki } \\
\text { penataan material }\end{array}$ & 5 & 240 \\
\hline & & & & $\begin{array}{l}\text { Operator malas } \\
\text { menempatkan } \\
\text { material sesuai } \\
\text { dengan } \\
\text { ketentuan (batch } \\
\text { tertua) }\end{array}$ & 9 & $\begin{array}{l}\text { Melakukan briefing } \\
\text { rutin dan checker } \\
\text { harus memastikan } \\
\text { penempatan barang } \\
\text { pengembalian }\end{array}$ & 5 & 270 \\
\hline & & & & $\begin{array}{l}\text { Operator malas } \\
\text { memperbarui } \\
\text { kartu stock }\end{array}$ & 5 & $\begin{array}{l}\text { Melakukan } \text { briefing } \\
\text { rutin dan checker } \\
\text { selalu melakukan }\end{array}$ & 4 & 120 \\
\hline
\end{tabular}




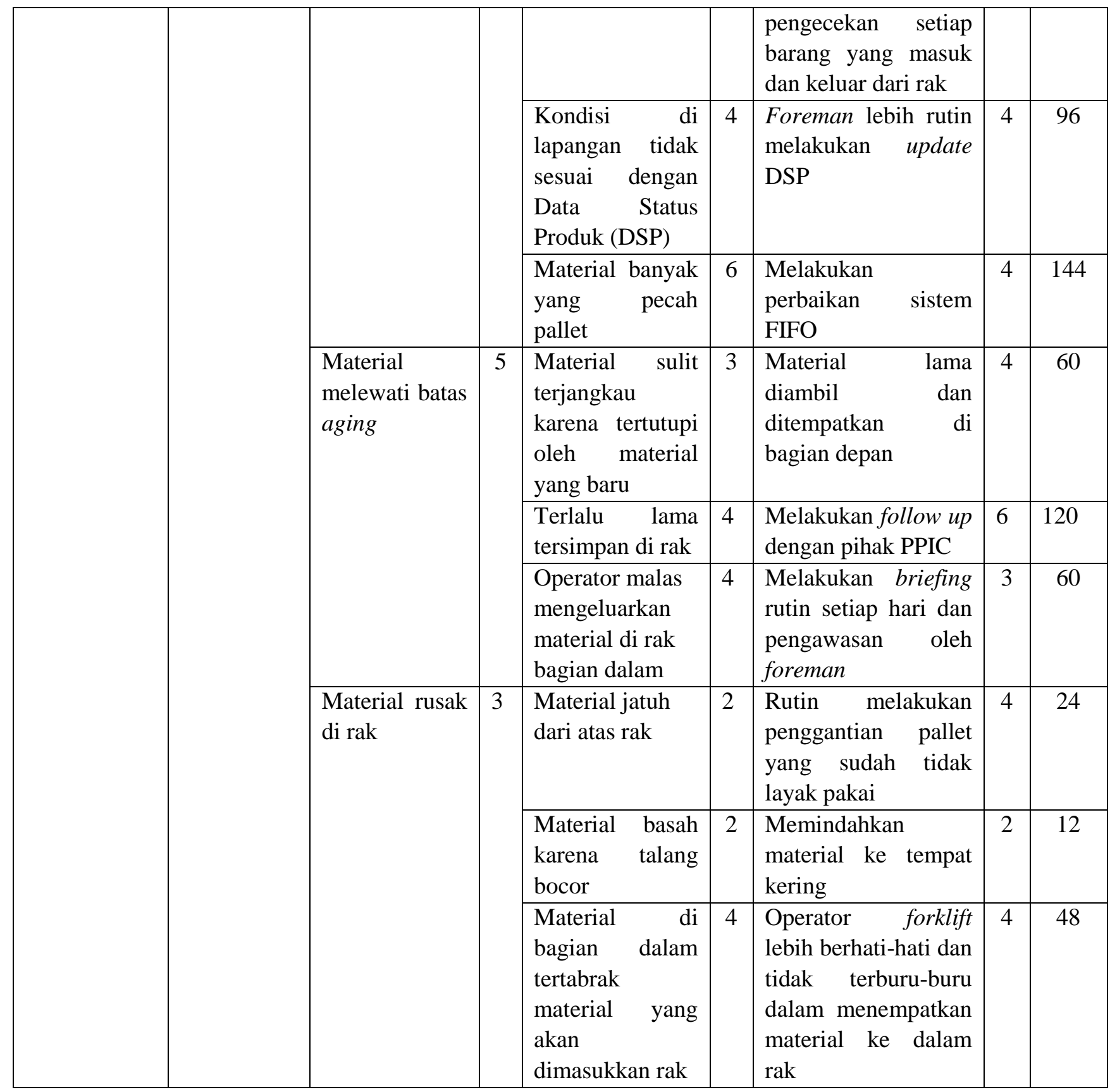

Menurut Putra (2012) severity merupakan kuantifikasi seberapa serius kondisi yang diakibatkan jika terjadi kegagalan yang akibatnya disebutkan dalam failure effect, severity ini dibuat dalam 10 skala (1-10) yang menunjukkan akibat yang tidak serius (1) sampai sangat serius (10). Occurrence merupakan tingkat kemungkinan terjadinya kegagalan, occurrence ini dibuat dalam 10 skala (1-10) yang menunjukkan akibat yang sangat jarang terjadi (1) sampai sangat mungkin terjadi (10). Sedangkan detection merupakan tingkat kemungkinan lolosnya penyebab kegagalan dari control yang sudah diberikan, detection ini dibuat dalam 10 skala (1-10) yang menunjukkan kemungkinan untuk lolos dari control kecil (1) sampai dengan kemungkinan untuk lolos dari control besar (10). Berdasarkan hasil analisis risiko tersebut, nilai RPN tertinggi yaitu pada penyebab potensi kegagalan operator malas menempatkan material sesuai dengan ketentuan (batch tertua). Maka penyebab potensi kegagalan tersebut akan dipriotitaskan untuk diselesaikan dengan mencari solusi atas permasalahan terjadinya material scrap pada seksi Warehouse Packaging Marsho PT. SMART Tbk. Surabaya. Menurut Stematis (1995) dalam Hanif dkk. (2015) RPN menegaskan tingkat prioritas dari suatu failure. Nilai RPN tersebut digunakan untuk meranking kegagalan proses yang potensial (Puspitasari, 2014).

\subsection{Improve}

Setelah akar penyebab dari masalah penyebab material scrap maka langkah selanjutnya adalah mencari solusi atas permasalahan tersebut. Langkah-langkah dalam melakukan perbaikan untuk minimalisasi material scrap menggunakan metode Five Why's Analysis. Berikut merupakan Five Why's Analysis penyebab material scrap. 
Tabel 3. Five Why's Analysis Penyebab Material Scrap Pada Seksi Warehouse Packaging Marsho

\begin{tabular}{|c|c|}
\hline Pertanyaan & Keterangan \\
\hline $\begin{array}{l}\text { Mengapa penempatan material tidak sesuai dengan } \\
\text { ketentuan (batch tertua)? }\end{array}$ & $\begin{array}{l}\text { Karena operator malas menempatkan material sesuai } \\
\text { dengan ketentuan (batch tertua) dan pihak checker } \\
\text { tidak rutin mengecek kesesuaian kartu stock dengan } \\
\text { Data Status Produk (DSP) serta penempatan } \\
\text { pengembalian material sisa produksi. }\end{array}$ \\
\hline $\begin{array}{l}\text { Mengapa operator malas menempatkan material } \\
\text { sesuai dengan ketentuan (batch tertua) dan checker } \\
\text { tidak rutin mengecek kesesuaian kartu stock dengan } \\
\text { Data Status Produk (DSP) serta penempatan } \\
\text { pengembalian material sisa produksi? }\end{array}$ & $\begin{array}{l}\text { Karena hal tersebut sudah menjadi kebiasaan sejak } \\
\text { dulu baik dari pihak operator maupun pihak checker } \\
\text { pada seksi Warehouse Packaging Marsho. }\end{array}$ \\
\hline $\begin{array}{l}\text { Mengapa penempatan material tidak sesuai dengan } \\
\text { ketentuan (batch tertua) dan pengecekan kesesuaian } \\
\text { kartu stock dengan Data Status Produk (DSP) yang } \\
\text { tidak rutin sudah menjadi kebiasaan sejak dulu? }\end{array}$ & $\begin{array}{l}\text { Karena minimnya briefing setiap hari sebelum } \\
\text { kegiatan operasional dimulai sejak dulu. }\end{array}$ \\
\hline $\begin{array}{l}\text { Mengapa minim briefing setiap hari sebelum kegiatan } \\
\text { operasional dimulai? }\end{array}$ & $\begin{array}{l}\text { Karena pihak PIC Area Warehouse Packaging } \\
\text { Marsho belum rutin melakukan briefing sebelum } \\
\text { kegiatan operasional dimulai dan sejauh ini briefing } \\
\text { hanya dilakukan sebatas jika akan diadakannya audit } \\
\text { pada seksi Warehouse Packaging Marsho. }\end{array}$ \\
\hline $\begin{array}{l}\text { Mengapa pihak PIC Area Warehouse Packaging } \\
\text { Marsho belum rutin melakukan briefing sebelum } \\
\text { kegiatan operasional dimulai? }\end{array}$ & $\begin{array}{l}\text { Karena pihak PIC Area merasa sungkan jika harus } \\
\text { mengarahkan pekerja pada seksi Warehouse } \\
\text { Packaging Marsho dikarenakan kebanyakan pekerja } \\
\text { pada seksi Warehouse Packaging Marsho lebih tua/ } \\
\text { senior dibanding dirinya serta kurangnya pengawasan } \\
\text { dari pihak section head Warehouse Packaging } \\
\text { mengenai pembiasaan briefing tersebut. }\end{array}$ \\
\hline
\end{tabular}

Berdasarkan uraian dari analisis Five Why's, maka solusi yang dapat direkomendasikan untuk meminimalisasi penyebab material scrap pada seksi Warehouse Packaging Marsho adalah sebagai berikut :

a. Pihak operator mulai membiasakan diri untuk menempatkan material sesuai dengan ketentuan (batch tertua).

b. Pihak checker lebih rutin melakukan pengecekan kesesuaian kartu stock dengan Data Status Produk (DSP) serta penempatan pengembalian material sisa produksi setiap akan melakukan pergantian shift.

c. Briefing tidak hanya dilakukan sebatas jika akan diadakannya audit pada seksi Warehouse Packaging Marsho saja.

d. Pihak PIC Area Warehouse Packaging Marsho lebih rutin dalam melakukan briefing kepada pekerja pada seksi Warehouse Packaging Marsho sebelum kegiatan operasional dimulai.

e. Pihak Section Head Warehouse Packaging lebih rutin melakukan pengawasan mengenai pembiasaan briefing oleh pihak PIC Area Warehouse Packaging Marsho sebelum kegiatan operasional dimulai.

\subsection{Control}

Setelah dilakukan suatu tindakan perbaikan berupa usulan perbaikan terhadap hasil analisis Five Why's penyebab material scrap pada seksi Warehouse Packaging Marsho, tahap selanjutnya adalah melakukan adanya pengendalian dari hasil-hasil perbaikan menggunakan metode DMAIC. Tanpa adanya suatu pengendalian terhadap hasil-hasil perbaikan tersebut, proses perbaikan tidak akan mencapai hasil yang diharapkan. Upaya pengendalian yang akan dilakukan adalah adanya pengendalian mulai dari pihak PIC Area Warehouse Packaging Marsho dan pihak Section Head Warehouse Packaging. Dengan adanya usulan perbaikan dan uapaya pengendalian yang akan dilakukan kedepannya, diharapkan dapat meminimalisasi permasalahan adanya material scrap pada seksi Warehouse Packaging Marsho PT. SMART Tbk. Surabaya. 


\section{Simpulan}

Berdasarkan hasil dari setiap tahapan metode DMAIC, pada tahapan define bagian yang dapat menimbulkan terjadinya material scrap terdapat pada bagian operator Warehouse Packaging. Pada tahapan measure, penyebab material scrap yang harus diprioritaskan untuk diselesaikan adalah discontinue dan sisa produksi. Pada tahapan analyse, nilai RPN terbesar yaitu pada penyebab potensi kegagalan operator malas menempatkan material sesuai dengan ketentuan (batch tertua). Pada tahapan improve, usulan yang diberikan ditujukan kepada pihak operator, checker, PIC Area Warehouse Packaging Marsho, dan Section Head Warehouse Packaging Marsho agar melakukan usulan yang telah diberikan. Sedangkan pada tahapan control, upaya pengendalian harus dilakukan terhadap hasil-hasil perbaikan menggunakan metode DMAIC yang telah diberikan.

Keterbatasan pada penelitian ini adalah peneliti mengasumsikan bahwa faktor penggangu (block) terhadap pemberian nilai pada Severity (S), Occurrence (O), dan Detection (D) tidak ada. Sehingga penelitian berikutnya diharapkan mempertimbangkan faktor pengganggu (block) terhadap pemberian nilai pada Severity (S), Occurrence (O), dan Detection (D) sehingga hasil penilaian ketiga faktor tersebut yang diperoleh lebih valid.

\section{Daftar Pustaka}

Adrianto, W., dan Kholil, M. (2015). Analisis Penerapan Lean Production Process Untuk Mengurangi Lead Time Process Perawatan Engine (Studi Kasus PT. GMF Aeroasia). Jurnal Optimasi Sistem Industri, Vol. 4, hal. 299-309.

Amperajaya, M. D., dan Daryanto. (2007). Identifikasi Penyebab Cacat Pulley Pada Proses Pengecoran di PT Himalaya Nabeya Indonesia Dengan Metode FMEA \& RCA. Jurnal Inovisi, Vol. 6, hal. 54-69.

Basuki, M., Susanto, R., B., dan Herianto, H., P. (2015). Analisis Risiko Kegiatan Bongkar Muat Sebagai Komponen Dwelling Time Di Pelabuhan. Seminar Nasional Sains dan Teknologi Terapan III, hal. 511517.

Breyfogle III, Forrest W. (1999). Implementing Six Sigma : Smarter Solutions Using Statistical Methods, New York : John Wiley \& Sons, Inc.

Gultom, S., Sinaga, T., S., dan Sinulingga, S. (2013). Studi Pengendalian Mutu Dengan Menggunakan Metode Lean Six Sigma Pada PT. XYZ. E-Jurnal Teknik Industri FT USU, Vol. 3, hal. 23-30.

Hanif, R., Y., Rukmi, H., S., dan Susanty, S. (2015). Perbaikan Kualitas Produk Keraton Luxury Di PT. X Dengan Menggunakan Metode Failure Mode and Effect Analysis (FMEA) dan Fault Tree Analysis (FTA). Jurnal Teknik Industri Itenas, Vol. 3, hal. 137-147.

Hariastuti, N., L., P. (2015). Analisis Pengendalian Mutu Produk Guna Meminimalisasi Produk Cacat. Seminar Nasional IENACO, hal. 268-275.

Nasution, S., dan Sodikin, R., D. (2018). Perbaikan kualitas proses produksi karton box dengan menggunakan metode DMAIC dan Fuzzy FMEA. Jurnal Sistem Teknik Industri, Vol. 20, hal. 36-47.

Puspitasari, N., B., dan Martanto, A. (2014). Penggunaan FMEA Dalam Mengidentifikasi Resiko Kegagalan Proses Produksi Sarung ATM (Alat Tenun Mesin) (Studi Kasus PT. Asaputex Jaya Tegal). Jurnal TI Undip, Vol. 9, hal. 93-98.

Putra, E., S. (2012). Sistem Pendukung Keputusan Dalam Mengurangi Stok Poy Downgrade Menggunakan Metode Six Sigma Dengan Tools FMEA pada PT. MGT. STIKOM

Rusdianto, A., S., Novijanto, N., dan Alihsany, R. (2011). Penerapan Statistical Quality Control (SQC) Pada Pengolahan Kopi Robusta Cara Semi Basah. J Agrotek, Vol. 5, hal. 1-10.

Siregar, M., T., dan Mutiara, T. (2019). Perbaikan proses di dalam gudang menggunakan metode DMAIC pada PT. Dakota Logistik Indonesia. Jurnal PRAXIS, Vol. 1, hal. 139-151.

Soetjitro, P. (2010). Instrumen Total Quality Management (TQM) Sebagai Pilihan Alat Pengendalian. VALUE $A D D E D$, Vol. 6, hal. 49-60.

Tebae, I., A., Karamoy, H., dan Runtu, T. (2016). Perlakuan Akuntansi Terhadap Sisa Bahan Pada PT. Multi Nabati Sulawesi. Jurnal EMBA, Vol. 4, hal. 1431-1441.

Utami, I., Solikhah, R., dan Istadi, I. (2012). Sintesa Katalis Super Asam $\mathrm{SO}_{4}{ }^{2-} / \mathrm{ZnO}$ Untuk Produksi Biodiesel Dari Minyak Kelapa Sawit. Jurnal Teknologi Kimia dan Industri, Vol. 1, hal. 69-78.

Wahyani, W., Chobir, A., dan Rahmanto, D., D. (2010). Penerapan metode six sigma dengan konsep DMAIC sebagai alat pengendali kualitas. Prosiding Seminar Nasional Manajemen Teknologi XII, hal. 1-14. 
8 Performa: Media IImiah Teknik Industri Vol. 18, No. 1

Wibisono, Y., Y., dan Suteja, T. (2013). Implementasi metode DMAIC six sigma dalam perbaikan mutu di industry kecil menengah: studi kasus perbaikan mutu produk spring adjuster di PT. X. Seminar Nasional IENACO-2013, hal. 1-8.

Yunita, N., dan Adi, P. (2019). Identifikasi proses produksi komponen guide dengan metode DMAIC pada supplier PT. X. Jurnal Titra, Vol. 7, hal. 1-6. 